\title{
Critical Importance of a One Health Approach to Antimicrobial Resistance
}

\author{
Allison White ${ }^{1}$ and James M. Hughes ${ }^{2}$ \\ ${ }^{1}$ EcoHealth Alliance, $460 \mathrm{~W}$ 34th Street 17th Floor, New York, NY 10001 \\ ${ }^{2}$ Emory Antibiotic Resistance Center, School of Medicine and Rollins School of Public Health, Emory University, Atlanta, GA
}

Antimicrobial resistance (AMR) is a complex, multifaceted problem that threatens human and animal health, the global economy, and national and global security. In the USA, an estimated 2 million drug-resistant infections occur annually, accounting for 8 million extra hospital days, 23,000 deaths, and $\$ 20$ billion in direct healthcare costs (Hughes 2011; Centers for Disease Control and Prevention 2013). Worldwide, AMR is increasing (Klein et al. 2018); if current trends continue unabated, there could be as many as 10 million annual AMR-associated deaths from a wide array of infections ${ }^{1}$ by 2050 (Review on Antimicrobial Resistance 2016). The World Health Organization (WHO) has included AMR as one of the top ten threats to global health in 2019 (World Health Organization 2019).

Two recent examples highlight the threat of emergence and rapid geographic dissemination of antibiotic resistance genes. An enzyme that confers resistance to a wide range of antibiotics, New Delhi metallo-beta-lactamase 1 (NDM-1), has emerged in the Indian subcontinent and spread to the UK as a result of medical tourism after first being detected in 2008 (Yong et al. 2009). The NDM-1 gene was subsequently detected in surface and tap water samples in India in 2010 and in the environment in Bangladesh, indicating

Published online: June 28, 2019

Correspondence to: Allison White, e-mail: white@ecohealthalliance.org

${ }^{1}$ Estimate based on work of two modeling groups focused on infections caused by a subset of drug-resistant bacteria including M. tuberculosis, drug-resistant HIV infection, and drug-resistant malaria infections. the potential for environmental origin and worldwide spread of this gene and its variants (Walsh et al. 2011; Islam et al. 2017; Khan et al. 2017). The NDM-1 gene has recently been identified in nutrient-rich Arctic soil of a remote Norwegian archipelago, raising the possibility of spread by feces from migratory birds (McCann et al. 2019). The MCR-1 (mobilized colistin resistance-1) gene, a plasmidborne gene conferring colistin resistance, was identified in pigs in China in 2014 (Liu et al. 2016) and has subsequently spread to dozens of other countries (Marston et al. 2016; Wang et al. 2018).

The purpose of this commentary is to highlight the importance of an integrated and holistic multisectoral One Health approach in combating AMR (Fig. 1) and in particular, the need for better integration of environmental, aquatic, and wildlife issues into current approaches (Andersson and Hughes 2014; Lammie and Hughes 2016; Robinson et al. 2016). Recent national and multinational strategies to address the urgency of AMR include the United States National Action Plan for combating antibiotic-resistant bacteria (White House 2015), World Health Organization (WHO) Global Action Plan on Antimicrobial Resistance (World Health Organization 2015), Declaration from the 2016 high-level meeting on antimicrobial resistance at the United Nations General Assembly (OPGA/ WHO/FAO/OIE 2016), and the FAO/OIE/WHO Tripartite Collaboration (FAO/OIE/WHO 2017)—all of which stress the importance of a multisectoral One Health response. WHO's Global Antimicrobial Resistance Surveillance 


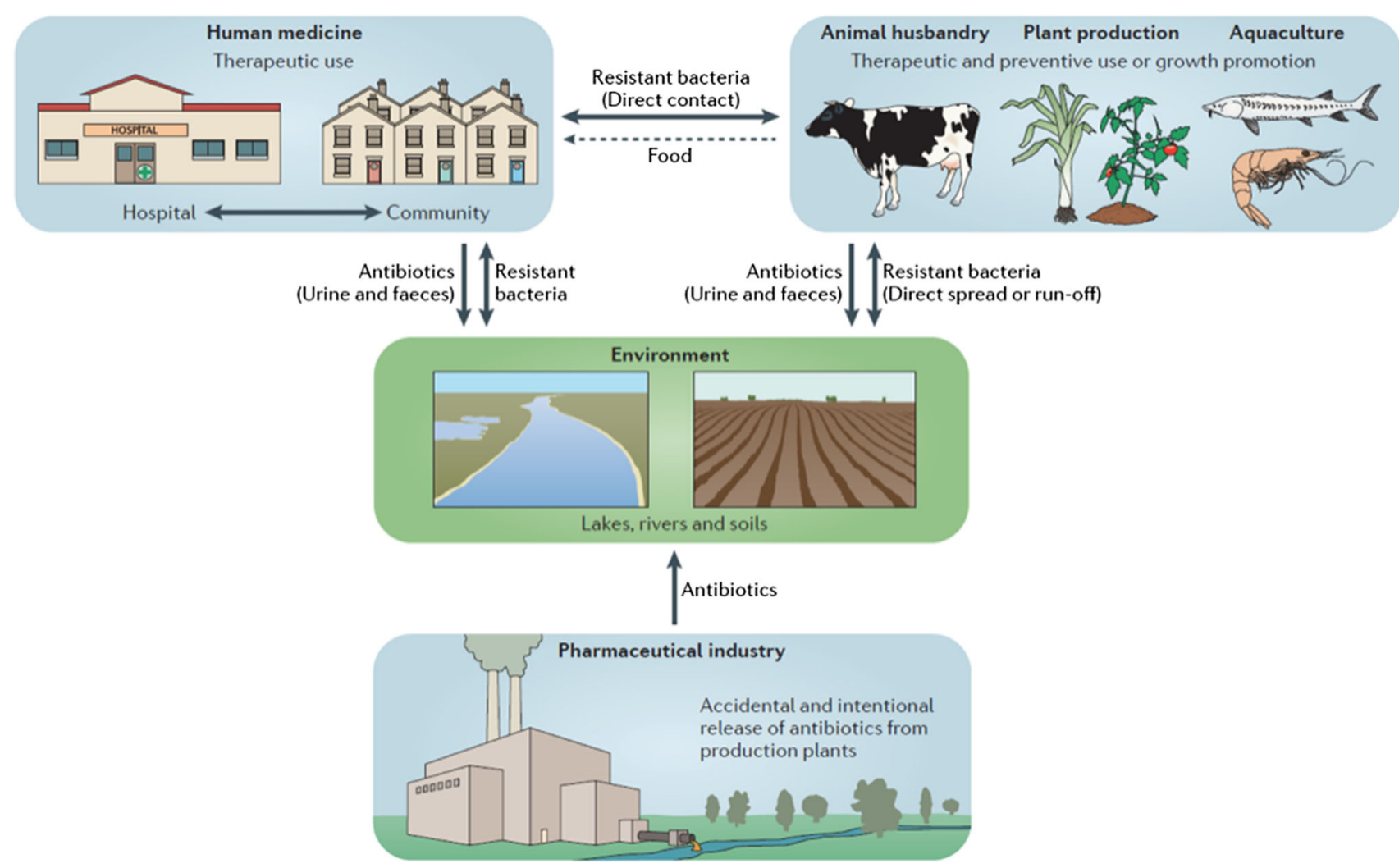

Fig. 1. Integrated ecosystem of the transfer and spread of antimicrobial resistance illustrates the critical importance of a One Health approach to the problem (Andersson and Hughes 2014)

System (GLASS), established in 2015, is helping countries strengthen national surveillance systems and provides more comprehensive standardized AMR surveillance data (Tornimbene et al. 2018). AMR is included as a priority in the World Bank's recent One Health operational framework (World Bank Group 2018). Recently, AMR has been the focus of several multisectoral meetings and conferences, including an AMR workshop at the recent Prince Mahidol Annual Conference in Bangkok, Thailand, a Forum on Microbial Threats of the U.S. National Academies of Sciences, Engineering and Medicine workshop (2017, 2018d), Ogawa et al. 2018), and the International One Health Congress in Saskatoon, Canada in 2018 (2018a).

Current One Health approaches to AMR focus primarily on reduction in antibiotic use in food animals. Recent systematic reviews and meta-analyses found associations between reduction in antibiotic use in food animals and a decrease in AMR in animals and limited evidence of some reduction in humans, recognizing that the complexity of the system prevents demonstration of a clear causal pathway and highlighting research gaps
(Hoelzer et al. 2017; Tang et al. 2017; Scott et al. 2018). This complexity was highlighted in the 2014 Report to the President on Combating Antibiotic Resistance (President's Council of Advisors on Science and Technology 2014; World Health Organization 2017).

WHO recently published new guidelines to limit antibiotic use in healthy food animals (World Health Organization 2017). While guidelines on antibiotic use in humans and food animals are important components of a One Health approach to AMR, a more comprehensive approach, which addresses wildlife, aquaculture, and especially the environment, is needed (2018c; Thakur and Gray 2019). Wildlife ecosystems are a potentially important reservoir of resistant organisms (AROs) and resistance genes (ARGs); drug-resistant E. coli have been found in multiple wildlife species as have isolates with plasmid-mediated resistance, which could be a result of environmental spread of human and livestock antibiotics (Carroll et al. 2015; Furness et al. 2017; Dolejska and Papagiannitsis 2018; Weiss et al. 2018). Wildlife may also be impacted by increasing antibiotic resistance; one study found human 
strains of drug-resistant Staphylococcus aureus in chimpanzees in sanctuaries, indicating that antimicrobial use and resistance in humans may impact nonhuman primates (Schaumburg et al. 2012). Wildlife populations have the potential to serve as sentinels for resistance resulting from environmental contamination, human use, and livestock use. Engaging wildlife and conservation colleagues in development and implementation of AMR surveillance and prevention strategies should be a priority.

While limited data on the public health impact of antibiotic use in aquaculture exist, it has been suggested that administration of antibiotics in aquatic systems can promote the development of resistance (Cabello et al. 2016). Studies have found ARGs in aquatic systems and evidence of horizontal gene transfer from aquatic bacteria to human pathogens (Jiang et al. 2012; Tomova et al. 2015). Such use involves potentially large amounts of antibiotics that are widely dispersed in the aquatic environment providing containment challenges (Heuer et al. 2009).

Finally, this approach must address the roles that environmental contamination with AROs, ARGs, and antibiotic residues plays in AMR. Environmental contamination related to antibiotic administration in both humans and in food production (livestock, aquaculture, and cropland) through runoff has been identified in several studies (Kumar et al. 2005; Boxall 2012) and, as mentioned, has the potential to impact wildlife and other populations. However, a recent review of One Health networks concluded that environmental health expertise was underrepresented (Essack 2018; Khan et al. 2018), and there has been a recent call for inclusion of environmental issues in national action plans for AMR (Iossa and White 2018). Environmental pollution from antibiotic production facilities has been linked to contamination of the surrounding environment (Fick et al. 2009; Khan et al. 2013; Larsson 2014). A 2017 UN report highlighted AMR as an "emerging issue of environmental concern," focusing on the potential risk of contamination from agriculture (including aquaculture), improper disposal of antibiotics for human use, challenges in removing antibiotics by traditional water treatment measures, and pollution from pharmaceutical production (UNEP 2017). A 2015 review on AMR recommended environmental waste management as a key measure in combating resistance (Review on Antimicrobial Resistance 2015). A recent white paper from the Wellcome Trust focuses on the issue of AMR in the environment with action items including manufacturing waste, crop production, as well as use in humans and animals, highlighting the importance of the environment and the One Health nature of this challenge (2018c). Comprehensive AMR research, surveillance, and control efforts must incorporate an environmental assessment and monitoring component.

Given this complexity and the multiple routes of exposure, it is difficult to determine the relative contribution of different sectors to AMR in humans. The 2014 Report to the President's Council of Advisors on Science and Technology on combating antibiotic resistance concluded that while it appears clear that both human and animal use contribute to AMR, it is challenging to quantify the relative importance of each system to resistance development (President's Council of Advisors on Science and Technology 2014). This conclusion reinforces the importance of examining AMR through a One Health lens-as an issue impacting humans, livestock, wildlife, and the environment. While additional research on the mechanisms and pathways of AMR is urgently needed, enough is known now to focus research and control efforts on developing and evaluating methods to combat resistance as well as on the development of new drugs, alternative therapeutic approaches, treatments, vaccines, and rapid diagnostic tests.

There is a need for a comprehensive One Health research agenda to address AMR that incorporates human, animal, environmental, ecosystem, and wildlife perspectives and identifies key priorities for this research. Communication, collaboration, and public engagement are necessary for engaging partners and developing strategies to prevent the emergence and spread of resistance, recognizing the gaps that have existed and working to fill them. Strategies should be developed by representatives from these fields working together to ensure an integrative approach, leveraging the resources of current systems and networks and engaging persons with expertise from the environmental and wildlife sectors which have often been overlooked. A global AMR governance structure to guide these efforts has recently been proposed (Padiyara et al. 2018; Rochford et al. 2018).

We encourage EcoHealth readers to actively approach any AMR issue through a One Health lens and engage scientists, policy makers, industry leaders, and other professionals in AMR forums, meetings, or research groups, ensuring that environment and wildlife sectors are included in development and implementation of country AMR national action plans. USAID's IDEEAL and DEAL projects in Southeast Asia utilize this approach on the issue of land use change and health, incorporating human health and eco- 
nomics into development analyses and including public and private stakeholders-expanding the scope and highlighting additional perspectives in land use planning and management (Zambrana-Torellio et al. 2015, 2018b). We encourage research groups and funders to require plans for One Health integration of AMR and include representatives of all of these sectors in monitoring and evaluation efforts.

This One Health research agenda should acknowledge that multiple sectors play a role in the development and spread of AMR and focus efforts on actionable, impact driven research. We urge countries and networks at the forefront of AMR efforts to engage these additional stakeholders in developing such an agenda, recognizing that an effective strategy will have far-reaching benefits in minimizing the impact of this urgent problem on human and animal health, the environment, the global economy, and national and global security.

\section{ACKNOWLEDGEMENTS}

Allison White was supported by the United States Agency for International Development (USAID) Emerging Pandemic Threats PREDICT program.

\section{COMPLIANCE WITH ETHICAL STANDARDS}

CONFLICT OF INTEREST Dr. Hughes is a former president of the Infectious Diseases Society of America and currently serves on the Board of Directors of the EcoHealth Alliance and of the One Health Commission.

\section{REFERENCES}

(2017) National Academies of Science, Engineering, and Medicine Proceedings of a Workshop: Combating Antimicrobial Resistance: A One Health Approach to a Global Threat, Washington, DC: National Academies Press.

(2018a) The 5th International One Health Congress Programme. https://onehealthplatform.com/iohc/programme-by-track/154.

(2018b) DEAL Research-A Capacity Building. INDOHUN. htt ps://indohun.org/news/deal-research-a-capacity-building/.

(2018c) Initiatives for Addressing Antimicrobial Resistance in the Environment: Current Situation and Challenges. https://wellc ome.ac.uk/sites/default/files/antimicrobial-resistance-envir onment-report.pdf.

(2018d) Prince Mahidol Conference 2018 Side Meeting: A One Health Approach for Tackling Antimicrobial Resistance: Moving from Knowledge to Action. Bangkok, Thailand. http://pmac 2018.com/site/sidemeeting/schedule/SE007.
Andersson DI, Hughes D (2014) Microbiological effects of sublethal levels of antibiotics. Nature Reviews Microbiology 12:465478. https://doi.org/10.1038/nrmicro3270

Boxall ABA (2012) New and Emerging Water Pollutants arising from Agriculture, United Kingdom: Organisation for Economic Co-Operation and Development University of York. https://w ww.oecd.org/tad/sustainable-agriculture/.

Cabello FC, Godfrey HP, Buschmann AH, Dölz HJ (2016) Aquaculture as yet another environmental gateway to the development and globalisation of antimicrobial resistance. Lancet Infectious Diseases 16:e127-e133

Carroll D, Wang J, Fanning S, McMahon BJ (2015) Antimicrobial resistance in wildlife: implications for public health. Zoonoses and Public Health 62:534-542

Centers for Disease Control and Prevention (2013) Antibiotic resistance threats in the United States, 2013. US Department of Health Human Services. https://www.cdc.gov/drugresistance/p df/ar-threats-2013-508.pdf.

Dolejska M, Papagiannitsis CC (2018) Plasmid-mediated resistance is going wild. Plasmid 99:99-111. https://doi.org/10.1016/ j.plasmid.2018.09.010

Essack SY (2018) Environment: the neglected component of the one health triad. Lancet Planetary Health 2:e238-e239

FAO/OIE/WHO (2017) The Tripartite's Commitment-Providing multi-sectoral, collaborative leadership in addressing health challenges. FAO/OIE/WHO. https://www.who.int/zoonoses/tri partite_oct2017.pdf.

Fick J, Söderström H, Lindberg RH, Phan C, Tysklind M, Larsson D (2009) Contamination of surface, ground, and drinking water from pharmaceutical production. Environmental Toxicology and Chemistry 28:2522-2527

Furness LE, Campbell A, Zhang L, Gaze WH, McDonald RA (2017) Wild small mammals as sentinels for the environmental transmission of antimicrobial resistance. Environmental Research 154:28-34

Heuer OE, Kruse H, Grave K, Collignon P, Karunasagar I, Angulo FJ (2009) Human health consequences of use of antimicrobial agents in aquaculture. Clinical Infectious Diseases 49:1248-1253

Hoelzer K, Wong N, Thomas J, Talkington K, Jungman E, Coukell A (2017) Antimicrobial drug use in food-producing animals and associated human health risks: what, and how strong, is the evidence? BMC Veterinary Research 13:211

Hughes JM (2011) Preserving the lifesaving power of antimicrobial agents. Journal of the American Medical Association 305:1027-1028

Iossa G, White PC (2018) The natural environment: a critical missing link in national action plans on antimicrobial resistance. Bulletin of the World Health Organization 96:858-860. https://doi.org/10.2471/BLT.18.210898

Islam MA, Islam M, Hasan R, Hossain MI, Nabi A, Rahman M, Goessens WHF, Endtz HP, Boehm AB, Faruque SM (2017) Environmental spread of New Delhi metallo-beta-lactamase-1producing multidrug-resistant bacteria in Dhaka, Bangladesh. Applied and Environmental Microbiology 83:e00717-e00793. https://doi.org/10.1128/aem.00793-17

Jiang H-X, Tang D, Liu Y-H, Zhang X-H, Zeng Z-L, Xu L, Hawkey PM (2012) Prevalence and characteristics of $\beta$-lactamase and plasmid-mediated quinolone resistance genes in Escherichia coli isolated from farmed fish in China. Journal of Antimicrobial Chemotherapy 67:2350-2353

Khan AU, Maryam L, Zarrilli R (2017) Structure, genetics and worldwide spread of New Delhi metallo-beta-lactamase (NDM): 
a threat to public health. BMC Microbiology 17:101. https:// doi.org/10.1186/s12866-017-1012-8

Khan GA, Berglund B, Khan KM, Lindgren P-E, Fick J (2013) Occurrence and abundance of antibiotics and resistance genes in rivers, canal and near drug formulation facilities-a study in Pakistan. PLoS One 8:e62712

Khan MS, Rothman-Ostrow P, Spencer J, Hasan N, Sabirovic M, Rahman-Shepherd A, Shaikh N, Heymann DL, Dar O (2018) The growth and strategic functioning of One Health networks: a systematic analysis. Lancet Planetary Health 2:e264-e273

Klein EY, Van Boeckel TP, Martinez EM, Pant S, Gandra S, Levin SA, Goossens H, Laxminarayan R (2018) Global increase and geographic convergence in antibiotic consumption between 2000 and 2015. Proceedings of the National Academy of Sciences 115:E3463-E3470. https://doi.org/10.1073/pnas.1717295115

Kumar K, Gupta SC, Chander Y, Singh AK (2005) Antibiotic use in agriculture and its impact on the terrestrial environment. Advances in Agronomy 87:1-54

Lammie SL, Hughes JM (2016) Antimicrobial resistance, food safety, and one health: the need for convergence. Annual Review of Food Science and Technology 7:287-312

Larsson DGJ (2014) Pollution from drug manufacturing: review and perspectives. Philosophical Transactions of the Royal Society B: Biological Sciences 369:20130571. https://doi.org/10.1098/ rstb.2013.0571

Liu Y-Y, Wang Y, Walsh TR, Yi L-X, Zhang R, Spencer J, Doi Y, Tian G, Dong B, Huang X (2016) Emergence of plasmid-mediated colistin resistance mechanism MCR-1 in animals and human beings in China: a microbiological and molecular biological study. Lancet Infectious Diseases 16:161-168

Marston HD, Dixon DM, Knisely JM, Palmore TN, Fauci AS (2016) Antimicrobial resistance. JAMA 316:1193-1204. https:// doi.org/10.1001/jama.2016.11764

McCann CMB, Christgen JA, Roberts J-Q, Su KE, Arnold ND, Gray Y-G, Zhu, Graham DW (2019) Understanding drivers of antibiotic resistance genes in High Arctic soil ecosystems. Environment International 125:497-504

Ogawa VA, Shah CM, Hughes JM, King LJ (2018) Prioritizing a one health approach in the immediate fight against antimicrobial resistance. EcoHealth . https://doi.org/10.1007/s10393-0181325-6

OPGA/WHO/FAO/OIE (2016) High-Level Meeting on Antimicrobial Resistance. https://www.un.org/pga/71/2016/09/21/pres s-release-hl-meeting-on-antimicrobial-resistance/.

Padiyara P, Inoue H, Sprenger M (2018) Global governance mechanisms to address antimicrobial resistance. Infectious Diseases: Research and Treatment 11:1178633718767887

President's Council of Advisors on Science and Technology (2014) Report to the President on Combating Antibiotic Resistance, Washington, DC: Executive Office of the President, President's Council of Advisors on Science and Technology.

Review on Antimicrobial Resistance (2015) Antimicrobials in agriculture and the environment: reducing unnecessary use and waste. https://amr-review.org/sites/default/files/Antimicrobial s\%20in\%20agriculture\%20and\%20the\%20environment $\% 20-\%$ 20Reducing\%20unnecessary\%20use $\% 20$ and\%20waste.pdf.

Review on Antimicrobial Resistance (2016) Tackling drug-resistant infections globally: Final report and recommendations. h ttps://amr-review.org/sites/default/files/160525_Final\%20paper _with\%20cover.pdf.

Robinson T, Bu D, Carrique-Mas J, Fèvre E, Gilbert M, Grace D, Hay S, Jiwakanon J, Kakkar M, Kariuki S (2016) Antibiotic resistance is the quintessential One Health issue. Transactions of the Royal Society of Tropical Medicine and Hygiene 110:377-380

Rochford C, Sridhar D, Woods N, Saleh Z, Hartenstein L, Ahlawat H, Whiting E, Dybul M, Cars O, Goosby E (2018) Global governance of antimicrobial resistance. Lancet 391:1976-1978

Schaumburg F, Mugisha L, Peck B, Becker K, Gillespie TR, Peters G, Leendertz FH (2012) Drug-resistant human Staphylococcus aureus in sanctuary apes pose a threat to endangered wild ape populations. American Journal of Primatology 74:1071-1075

Scott AM, Beller E, Glasziou P, Clark J, Ranakusuma RW, Byambasuren O, Bakhit M, Page SW, Trott D, Mar CD (2018) Is antimicrobial administration to food animals a direct threat to human health? A rapid systematic review International Journal of Antimicrobial Agents 52:316-323. https://doi.org/ 10.1016/j.ijantimicag.2018.04.005

Tang KL, Caffrey NP, Nóbrega DB, Cork SC, Ronksley PE, Barkema HW, Polachek AJ, Ganshorn H, Sharma N, Kellner JD (2017) Restricting the use of antibiotics in food-producing animals and its associations with antibiotic resistance in foodproducing animals and human beings: a systematic review and meta-analysis. Lancet Planetary Health 1:e316-e327

Thakur S, Gray GC (2019) The mandate for a global "one health" approach to antimicrobial resistance surveillance. The American Journal of Tropical Medicine and Hygiene 100:227. https:// doi.org/10.4269/ajtmh.18-0973

Tomova A, Ivanova L, Buschmann AH, Rioseco ML, Kalsi RK, Godfrey HP, Cabello FC (2015) Antimicrobial resistance genes in marine bacteria and human uropathogenic Escherichia coli from a region of intensive aquaculture. Environmental Microbiology Reports 7:803-809

Tornimbene B, Eremin S, Escher M, Griskeviciene J, Manglani S, Pessoa-Silva CL (2018) WHO global antimicrobial resistance surveillance system early implementation 2016-17. Lancet Infectious Diseases 18:241-242

UNEP (2017) Frontiers 2017 Emerging Issues of Environmental Concern. United Nations Environment Programme, Nairobi. h ttp://wedocs.unep.org/handle/20.500.11822/22255.

Walsh TR, Weeks J, Livermore DM, Toleman MA (2011) Dissemination of NDM-1 positive bacteria in the New Delhi environment and its implications for human health: an environmental point prevalence study. Lancet Infectious Diseases 11:355-362

Wang R, Dorp L, Shaw LP, Bradley P, Wang Q, Wang X, Jin L, Zhang Q, Liu Y, Rieux A (2018) The global distribution and spread of the mobilized colistin resistance gene mcr-1. Nature Communications 9:1179

Weiss D, Wallace RM, Rwego IB, Gillespie TR, Chapman CA, Singer RS, Goldberg TL (2018) Antibiotic-Resistant Escherichia coli and Class 1 integrons in humans, domestic animals, and wild primates in rural Uganda. Applied and Environmental Microbiology 84:e1618-e01632. https://doi.org/10.1128/ aem.01632-18

White House (2015) National action plan for combating antibiotic-resistant bacteria, Washington, DC: White House. https:// obamawhitehouse.archives.gov/sites/default/files/docs/national_ action_plan_for_combating_antibotic-resistant_bacteria.pdf.

World Bank Group (2018) Operational Framework for Strengthening Human, Animal, and Environmental Public Health Systems at their Interface, Washington, DC: International Bank for Reconstruction and Development/The World Bank. http://doc uments.worldbank.org/curated/en/703711517234402168/pdf/12 
3023-REVISED-PUBLIC-World-Bank-One-Health-Framewor k-2018.pdf.

World Health Organization (2015) Global action plan on antimicrobial resistance. World Health Organization. http://w ww.who.int/iris/handle/10665/193736.

World Health Organization (2017) WHO guidelines on use of medically important antimicrobials in food-producing animals. Licence: CC BY-NC-SA 3.0 IGO, Geneva: World Health Organization.

World Health Organization (2019) Ten threats to global health in 2019. https://www.who.int/emergencies/ten-threats-to-global-h ealth-in-2019.
Yong D, Toleman MA, Giske CG, Cho HS, Sundman K, Lee K, Walsh TR (2009) Characterization of a new metallo- $\beta$-lactamase gene, blaNDM-1, and a novel erythromycin esterase gene carried on a unique genetic structure in Klebsiella pneumoniae sequence type 14 from India. Antimicrobial Agents and Chemotherapy 53:5046-5054

Zambrana-Torellio C, Lee KD, Hughes T, Murray KA, Loh E, Epstein JH, Schar D, Daszak P (2015) Land use change and economic cost of emerging infectious diseases, Montpellier: International Congress for Conservation Biology 